\title{
Late-onset diffuse lamellar keratitis 4 years after femtosecond laser-assisted small incision lenticule extraction: a case report
}

\author{
Meiyan $\mathrm{Li}^{1 \dagger}$, Dong Yang ${ }^{1 \dagger}$, Yingjun Chen ${ }^{1}$, Meng $\mathrm{Li}^{1}$, Tian Han ${ }^{1}$, Xingtao Zhou ${ }^{1 *}$ (D) and Katherine $\mathrm{Ni}^{2}$
}

\begin{abstract}
Background: To report a first case of late-onset diffuse lamellar keratitis (DLK) occurring 4 years after femtosecond laser-assisted small incision lenticule extraction (SMILE).

Case presentation: A 41-year-old man who underwent SMILE 4 years prior developed DLK in the right eye 1 day after he was struck in the eye by a finger while playing with his son. Slim-lamp microscopy and anterior segment optical coherence tomography (AS-OCT) were used to evaluate the cornea of the right eye. Slit-lamp examination of the right eye revealed epithelial exfoliation and stage 3 DLK with diffuse, dot-like, granular haze in the interface between the cap and stromal bed. After intensive treatment with topical corticosteroids, the DLK resolved and corneal transparency was achieved.

Conclusions: This case indicates that DLK can occur several years after SMILE. Ocular trauma may be a risk factor for the development of DLK. The prognosis is usually favorable with early diagnosis and treatment with topical corticosteroids.
\end{abstract}

Keywords: Late-onset, DLK, Smile, Trauma

\section{Background}

Diffuse lamellar keratitis (DLK) is a condition in which a white blood cell infiltrate accumulates between the flap and stromal bed, and is typically a potential early complication after laser in situ keratomileusis (LASIK) [1, 2]. It has also been reported with an incidence of 1 in 62 after small incision lenticule extraction (SMILE) [3]. Late-onset DLK has been described in several studies after LASIK $[4,5]$, however most of these cases are likely due to a specific causative agent such as trauma or epithelial defects [6]. As far as we know, no paper about late-onset DLK after SMILE has yet been described in the scientific literature. In this case report, we present a patient with late-onset DLK, induced by trauma occurring 4 years after SMILE.

\footnotetext{
* Correspondence: doctzhouxingtao@163.com

${ }^{\dagger}$ Equal contributors

'Key Lab of Myopia, Ministry of Health, Department of Ophthalmology, EYE \& ENT Hospital of Fudan University, Shanghai, China

Full list of author information is available at the end of the article
}

\section{Case presentation}

A 41-year-old man had undergone femtosecond laserassisted SMILE in the right eye on November 1, 2011 at the Department of Ophthalmology of Fudan University Eye and ENT Hospital (Shanghai, People's Republic of China). Preoperatively, refraction was $-8.75 /-1.00 \times 35$ in the right eye and his corrected distance visual acuity (CDVA) was 20/25. Keratometric readings (Pentacam; Oculus, Wetzlar, Germany) were 44.70/44.90 diopters. Central corneal thickness was $565 \mu \mathrm{m}$. No anterior and posterior segment abnormalities were observed. The femtosecond laser system (VisuMax, Carl Zeiss Meditec AG, Jena, Germany) was used to perform the SMILE procedure. The repetition rate was set to $500 \mathrm{kHz}$, with a pulse energy of $180 \mathrm{~nJ}$. The surgery was conducted uneventfully, as described in our previous report [7]. One day postoperatively, the uncorrected distance visual acuity (UDVA) was 20/50. At 6 months, it was $20 / 25$ and the CDVA was $20 / 25$ with a manifest refraction of $+0.25 /-0.75 \times 15$.

In August 2016, 58 months after the SMILE surgery, the patient noted a decline in visual acuity, accompanied by sharp jabbing pain in the right eye, starting 1 day 
after being struck in the right eye with a finger while playing with his young son. He presented to our hospital, where his UDVA was found to be 20/200 OD. Slitlamp examination of the right eye revealed epithelial exfoliation and stage 3 DLK with a diffuse, dot-like, granular haze in the interface between the cap and stromal bed. Anterior segment optical coherence tomography (AS-OCT) and slit-lamp findings at presentation are shown in Fig. 1. Bandage soft contact lens (ACUVE OASYS, Inc., FL, USA) was applied to the right eye. Prednisolone acetate $1.0 \%$ was prescribed 8 times daily

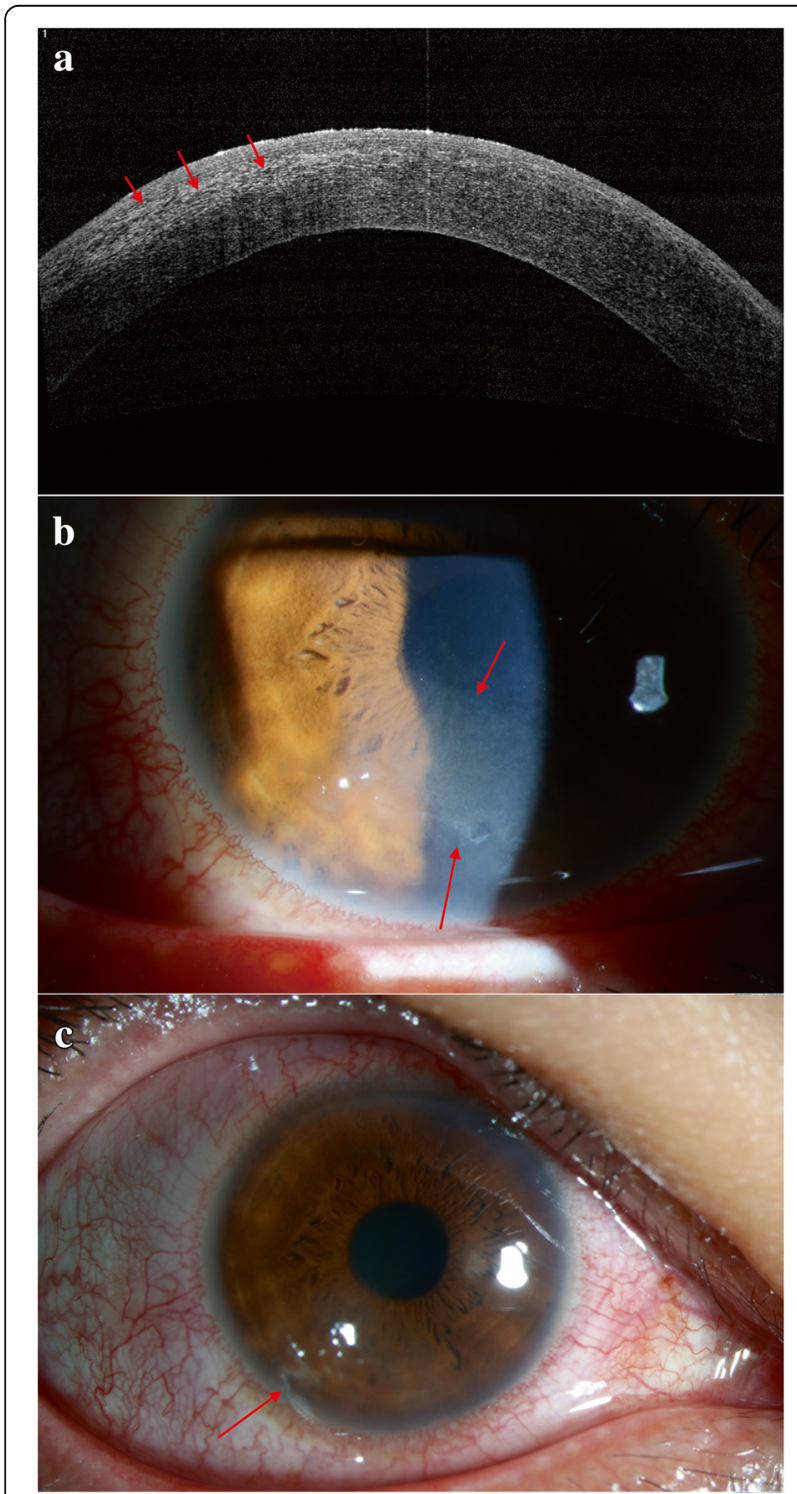

Fig. 1 The anterior segment optical coherence tomography (AS-OCT) showing (a) hyper reflection in the left corneal stromal bed (red arrow); slit-lamp photography showing diffuse, dot-like, and granular haze in the interface between cap and stromal bed (red arrow) (b) and epithelial exfoliation (red arrow), conjunctiva edema and hyperaemia of the right eye (c) at 1 day after trauma (58 months after SMILE) and tapered every day for the first three days, then 5 times daily for two days, along with levofloxacin eyedrops 4 times daily. Five days after initiating treatment, the pain has relieved and the UDVA increased to 20/80, the area of DLK was smaller and the epithelial defect was healed (Fig. 2). The bandage soft contact lens was discontinued. Prednisolone acetate $1.0 \%$ was prescribed 4 times daily and tapered every 2 days. Ten days after initiating treatment, the clinical signs of DLK had resolved. AS-OCT and slit-lamp images at day 10 are shown in Fig. 3. The UDVA returned to $20 / 25$ and the CDVA was 20/25 with a manifest refraction of $+0.25 /-0.75 \times 20$. Two weeks after the injury, the patient's UDVA returned to 20/25 in the right eye, and the prednisolone acetate was discontinued.

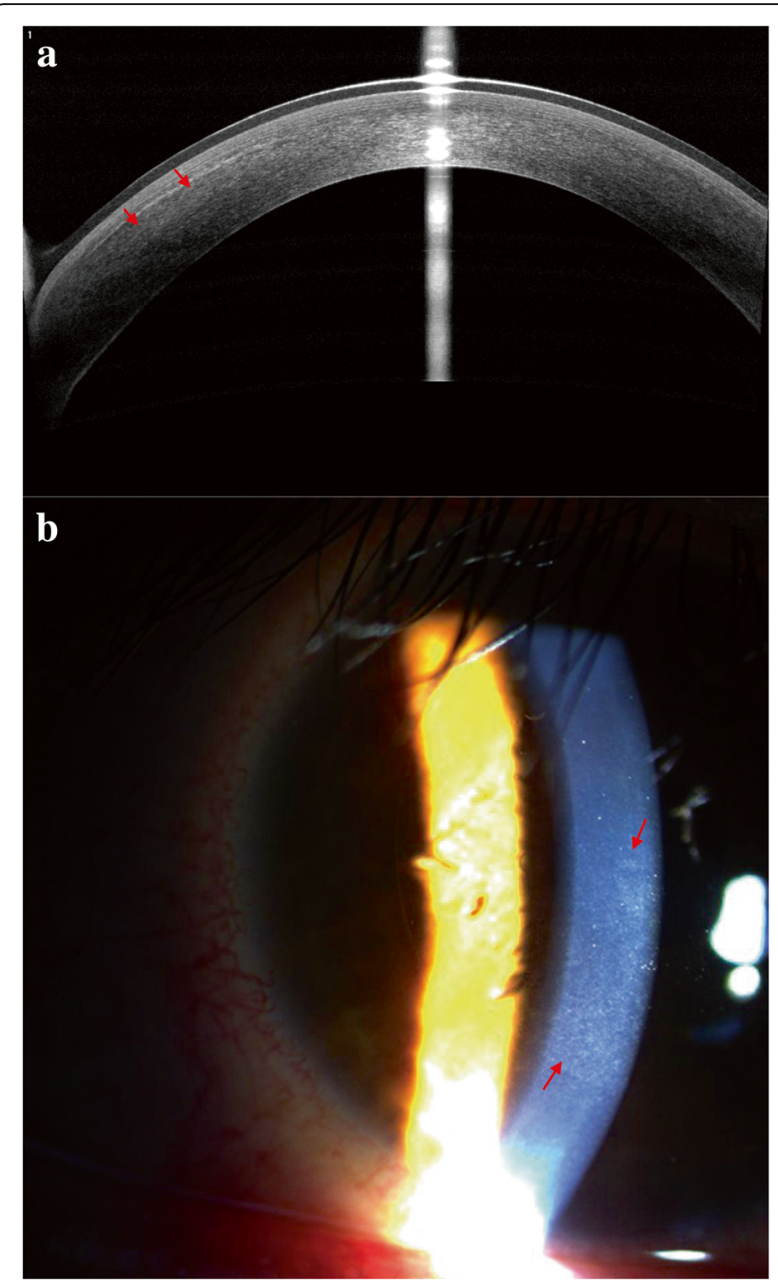

Fig. 2 The anterior segment optical coherence tomography (AS-OCT) showed (a) hyper reflection has reduced in the left corneal stromal bed (red arrow); slit-lamp photography showed diffuse, dot-like, and granular haze has relieved in the interface between cap and stromal bed (red arrow) (b) at 5 day after treatment 


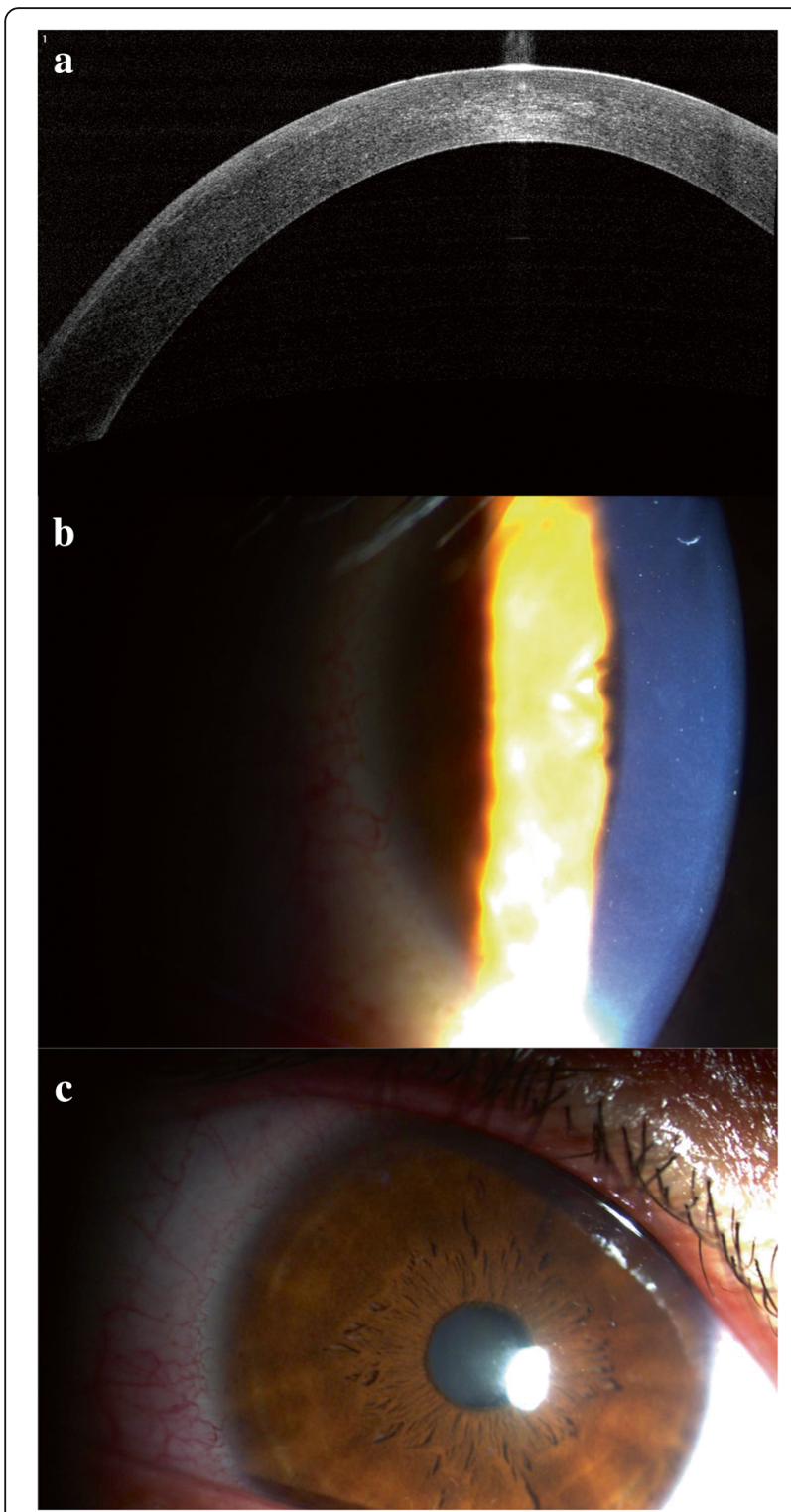

Fig. 3 The AS-OCT (a) and slit-lamp (b and $\mathbf{c}$ ) images of the right eye showed resolution of diffuse lamellar keratitis after corticosteroid treatment, at 10 days after trauma (58 months after SMILE)

\section{Discussion and conclusions}

Several reports have described cases of late-onset DLK induced by trauma after LASIK with flap displacement $[8,9]$. The majority of the reported cases, which occurred between 1 and 12 months postoperatively, were associated with a traumatic or spontaneous epithelial defect [10, 11]. Haw et al. have reported that epithelial injury could induce alterations in the metabolism and oxygenation of the cornea and allow more diffusion of inflammatory mediators from the tear film or alter the permeability of the limbal vasculature to inflammatory cells [10]. Our case illustrated the development of late-onset DLK 58 months after SMILE, induced by trauma in the eye. As SMILE leaves the anterior cornea intact, no flap displacement occurred due to the trauma.

Rana et al. [12] reported that late-onset stage 3 DLK after LASIK should be managed by lifting of the flaps and performing an interface washout, if the response to treatment with intensive topical steroids is poor. Zhao et al. [3] have described that with timely diagnosis and topical steroid administration, the prognosis for DLK occurring within a few days after SMILE is usually good and the refractive outcomes (UDVA, CDVA, and manifest refraction) are comparable to those without DLK, even in patients with stage 3 DLK. In our study, we report a case of late-onset stage 3 DLK after SMILE, which, like early-onset DLK after SMILE, responded well to treatment with topical corticosteroids.

Our study indicates that DLK may occur several years after SMILE, and may be induced by trauma. Early diagnosis and treatment is important for the prognosis of late-onset DLK, and the same principles of treatment may be applied to both late-onset and early-onset DLK after SMILE and LASIK.

\section{Abbreviations}

AS-OCT: Anterior segment optical coherence tomography; CDVA: Corrected distance visual acuity; DLK: Diffuse lamellar keratitis; LASIK: Laser in situ keratomileusis; SMILE: Small incision lenticule extraction; UDVA: Uncorrected distance visual acuity

\section{Acknowledgments}

None.

\section{Funding}

Supported by the Natural Science Foundation of China (Grant No. 81570879), Natural Science Foundation of China (Grant No. 81500753), 'Yangfan' project of Science and Technology of Shanghai (Grant No. 15YF1401800).

Availability of data and materials

All data generated or analysed during this study are included in this published article.

\section{Precis}

This study is the first reported case of late-onset DLK, occurring 4 years after SMILE. Ocular trauma is considered a risk factor to the development of DLK.

\section{Author contributions}

Concept and design (ML and XZ); analysis and interpretation (ML, DY and YC); writing the article (ML, and DY); critical revision of the article (ML, DY, YC, ML, $\mathrm{TH}, \mathrm{KN}$ and $\mathrm{XZ}$ ); final approval of the article (ML, DY, YC, ML, TH, KN and $\mathrm{XZ}$ ); data collection (YC and ML); literature research (DY). All authors read and approved the final manuscript.

Ethics approval and consent to participate Not applicable.

\section{Consent for publication}

Written informed consent was obtained from the patient for publication of this case report and accompanying images. A copy of the written consent is available for review by the Editor of this journal.

Competing interests

The authors declare that they have no competing interests. 


\section{Publisher's Note}

Springer Nature remains neutral with regard to jurisdictional claims in published maps and institutional affiliations.

\section{Author details}

'Key Lab of Myopia, Ministry of Health, Department of Ophthalmology, EYE \& ENT Hospital of Fudan University, Shanghai, China. ${ }^{2}$ School of Medicine, New York University, New York, USA.

Received: 7 June 2017 Accepted: 30 November 2017

Published online: 08 December 2017

\section{References}

1. Stulting RD, Randleman JB, Couser JM, Thompson KP. The epidemiology of diffuse lamellar keratitis. Cornea. 2004:23:680-8.

2. Johnson JD, Harissi-Dagher M, Pineda R, Yoo S, Azar DT. Diffuse lamellar keratitis: incidence, associations, outcomes, and a new classification system. J Cataract Refract Surg. 2001;27:1560-6.

3. Zhao J, He L, Yao P, et al. Diffuse lamellar keratitis after small-incision lenticule extraction. J Cataract Refract Surg. 2015;41:400-7.

4. Jin GJ, Lyle WA, Merkley KH. Late-onset idiopathic diffuse lamellar keratitis after laser in situ keratomileusis. J Cataract Refract Surg. 2005:31:435-7.

5. Kymionis GD, Diakonis VF, Bouzoukis DI, Lampropoulou I, Pallikaris Al. Idiopathic recurrence of diffuse lamellar keratitis after LASIK. J Refract Surg. 2007;23:720-1.

6. Randleman JB, Shah RDLASIK. Interface complications: etiology, management, and outcomes. J Refract Surg. 2012;28:575-86.

7. Li M, Zhao J, Miao H, et al. Mild decentration measured by a Scheimpflug camera and its impact on visual quality following SMILE in the early learning curve. Invest Ophthalmol Vis Sci. 2014;55:3886-92.

8. Schwartz GS, Park DH, Schloff S, Lane SS. Traumatic flap displacement and subsequent diffuse lamellar keratitis after laser in situ keratomileusis. J Cataract Refract Surg. 2001;27:781-3.

9. Aldave AJ, Hollander DA, Abbott RL. Late-onset traumatic flap dislocation and diffuse lamellar inflammation after laser in situ keratomileusis. Cornea. 2002:21:604-7.

10. Haw WW, Manche EE. Late onset diffuse lamellar keratitis associated with an epithelial defect in six eyes. J Refract Surg. 2000;16:744-8.

11. Weisenthal RW. Diffuse lamellar keratitis induced by trauma 6 months after laser in situ keratomileusis. J Refract Surg. 2000;16:749-51.

12. Rana M, Adhana P, llango B. Diffuse lamellar keratitis: confocal microscopy features of delayed-onset disease. Eye Contact Lens. 2015;41:e20-3.

\section{Submit your next manuscript to BioMed Central} and we will help you at every step:

- We accept pre-submission inquiries

- Our selector tool helps you to find the most relevant journal

- We provide round the clock customer support

- Convenient online submission

- Thorough peer review

- Inclusion in PubMed and all major indexing services

- Maximum visibility for your research

Submit your manuscript at www.biomedcentral.com/submit
Biomed Central 